EGU2020-20872

EGU General Assembly 2020

(c) Author(s) 2020. This work is distributed under

the Creative Commons Attribution 4.0 License.

\title{
The Use of Ultrasonic Tomography for the Non-destructive Assessment of Tree Trunks
}

\author{
Amir M. Alani ${ }^{1}$, James Chambers ${ }^{2}$, Paul Melarange ${ }^{3}$, Livia Lantini ${ }^{1}$, and Fabio Tosti ${ }^{1}$ \\ ${ }^{1}$ School of Computing and Engineering, University of West London (UWL), London, United Kingdom of Great Britain and \\ Northern Ireland (Amir.Alani@uwl.ac.uk; Livia.Lantini@uwl.ac.uk; Fabio.Tosti@uwl.ac.uk) \\ ${ }^{2}$ Tim Moya Associates, The Barn, Feltimores Park, Chalk Lane, Harlow, Essex CM17 OPF James.Chambers@tma- \\ consultants.co.uk) \\ ${ }^{3}$ thinktrees - arboricultural consultancy \& tree care, 8 Swinstead Court, Chalgrove, Oxfordshire, OX44 7TG \\ (admin@thinktrees.co.uk)
}

Assessing internal decay in tree trunks can be of crucial importance for industrial, environmental and public safety reasons [1]. To this effect, non-destructive testing (NDT) methods can provide information on the structural condition of trees with minimum intrusion. In this work, authors have analysed the capabilities of ultrasonic tomography in evaluating the internal structure of living trees, with a special focus on the identification of internal decay areas and tree bark inclusions.

The presented ultrasonic tomography provides an image of the distribution of the ultrasonic velocity of propagation within the investigated section of a mature horse chestnut (Aesculus hippocastanum). This technique has proven its viability to detect fungal decomposition [2]. However, there exist some open issues with regard to: a) the coupling of the transducers to the tree, b) the anisotropy of the wood, c) the signal attenuation and the resolution of the tomographic inversion. To overcome these challenges, research is underway to explore the integration and new data-fusion strategies with other NDT methods, such as ground penetrating radar (GPR), which have proven their effectiveness within this area of endeavour [3].

Within this context, data have been obtained from a "diseased" horse chestnut tree located at the Kensington Gardens - The Royal Parks - in London, UK, using two different ultrasonic equipment, i.e., the PICUS Sonic Tomograph and the Arbotom Sonic Tomograph. After compilation of data, the tree was felled and cut at the two sections where ultrasonic tomography tests were performed. In more detail, 12 sensors were arranged around the perimeter of the tree in compliance with the manufacturer's recommendations concerning the inspection methodology (sensors installed within the bark of the tree without any intrusion to the core of the tree). The adopted methodology takes to account the shape and size of the trunk [1]. The processed data were mapped against the cut sections of the tree for validity purposes.

Results presented in this abstract are part of a major ongoing research project that the authors have undertaken for the last three years. 


\section{Acknowledgements}

The authors would like to express their sincere thanks and gratitude to the following trusts, charities, organisations and individuals for their generosity in supporting this project: Lord Faringdon Charitable Trust,The Schroder Foundation,Cazenove Charitable Trust,Ernest Cook Trust,Sir Henry Keswick,lan Bond, P.F. Charitable Trust,Prospect Investment Management Limited,The Adrian Swire Charitable Trust,The John Swire 1989 Charitable Trust,The Sackler Trust, The Tanlaw Foundation, and The Wyfold Charitable Trust. We would like to thank also lan Rodger - Royal Parks Arboricultural Manager-for providing us with the tested tree. This paper is dedicated to the memory of our colleague and friend Jonathan West, one of the original supporters of this research project.

\section{References}

[1] Gilbert, G.S. et al. (2016). Use of sonic tomography to detect and quantify wood decay in living trees, Applications in Plant Sciences 4(12): 1600060.

[2] Bucur, V. Acoustics of Wood. CRC Press Inc., Boca Raton,Argentina (1995).

[3] Alani, A.M. et al. (2019). The Use of Ground Penetrating Radar and Microwave Tomography for the Detection of Decay and Cavities in Tree Trunks. Remote Sensing 11: 2073. 